\title{
Discurso de bienvenida
}

Muy buenos días a todos y todas. En nombre de la Universidad Centroamericana "José Simeón Cañas" quiero darles la más cordial bienvenida al Encuentro Nacional de Investigación, titulado "Futuro y retos de la investigación en $\mathrm{El}$ Salvador". Un importante evento organizado en el marco del 50 aniversario de la fundación de nuestra Universidad que nos permitirá "reflexionar cuál ha sido el aporte que la Universidad ha hecho al país, desde la investigación, a lo largo de estos primeros 50 años de vida de la UCA; y pensar en los retos estratégicos que la realidad actual y futura del país le están planteando a la investigación científica".

Para ello, permítanme saludar y dar la más cordial bienvenida a dos personas muy queridas y entrañables y con un claro protagonismo en la historia de esta Universidad y del país: el Ing. Román Mayorga Quiroz y al Dr. Héctor Dada.

- Ing. Román Mayorga Quiroz, coordinador del equipo que planificó el desarrollo de la
Andreu Oliva, S.J. Rector Universidad Centroamericana "José Simeón Cañas", UCA

UCA y rector de la Universidad en el período de 1975-1979. Después ha continuado aportando al desarrollo de la educación superior en Latinoamérica desde distintas instancias internacionales.

- Dr. Héctor Dada Hirezi, economista y político, cuenta con gran reconocimiento y respeto en nuestra Universidad y en la sociedad salvadoreña por su visión, honradez y vocación política al servicio de la gente. Ha sido profesor e investigador de la UCA; panelista y ponente en muchos eventos, y un gran conocedor de la realidad del país.

Ambos conocen muy bien la UCA, soy consciente además de que la aprecian, y conocen el tema del que hoy queremos hablar. Ellos nos ofrecerán la ponencia inaugural "50 años de investigación y los desafíos del país" que estoy seguro será de gran interés.

Muchas gracias por aceptar participar en este acto inaugural 
$y$ ofrecernos sus aportes en este proceso de reflexión.

Como pueden ver, este Encuentro Nacional sobre investigación, muestra el interés que la UCA ha tenido y tiene por la investigación. La vemos como una función sustantiva de la Universidad, que nos hace ser UCA y sin ella no alcanzaríamos a ser la universidad que deseamos ser.

Permítanme recordar la importancia de la investigación para la UCA.

La UCA debe investigar porque:

a) La investigación es una función que le es propia por ser universidad y un instrumento privilegiado para realizar su misión; sin la investigación, a la UCA no le sería posible realizar la misión que se ha trazado. La investigación es un deber ineludible para "Ilegar a identificar e interpretar, con el mayor rigor racional y científico posible, los aspectos clave que determinan la realidad actual, en orden a intervenir, de manera universitaria" (Misión de la Universidad Centroamericana "José Simeón Cañas", 2001, p. 35). La investigación nos permitirá incidir en la cultura y en la conciencia colectiva para impulsar un cambio social desde la perspectiva de las mayorías populares, para que estas puedan gozar de sus derechos humanos con plenitud. Ello implica profundizar en el conocimiento de la realidad, en el contexto que vivimos, para "esclarecer la situación existente y sus causas, así como también elaborar alternativas teóricas y prácticas que hagan posible la intervención transformadora" (Misión de la Universidad Centroamericana "José Simeón Cañas", 2001, p. 36).

Sin investigar la realidad, sin conocer los fenómenos que en ella se dan, sin poder explicar sus causas, no se podrá generar conocimiento ni aportar a la solución de los problemas que la realidad nos plantea. La investigación es, pues, una tarea que le corresponde a la Universidad como institución y deben realizarla todos los académicos que tiene capacidad para ello, sin excepción.

La investigación proporciona a la Universidad datos para sus valoraciones, para sus propuestas, para que su palabra sea eficaz y creíble.

b) Pero también es necesaria una investigación de calidad

Decía Ellacuría que la calidad de la investigación debe medirse en dos aspectos: 1) su pertinencia de cara a hacer posible la misión de la UCA y su capacidad transformadora; y 2) su racionalidad y el uso de las metodologías más adecuadas. La rigurosidad teórica y metodológica debe cuidarse en extremo. 
Toda investigación debe evaluarse tanto en su proceso como en su impacto transformador. Por otro lado, la investigación debe estar relacionada con las otras dos funciones de la Universidad; la proyección social y la docencia, y mantener con ellas un equilibrio adecuado.

c) $Y$ que a su vez sea pertinente, por ello, es necesaria una investigación práctica al servicio de la solución de los problemas del país

Para ser fiel a su tradición y misión, la investigación de la UCA debe ofrecer diagnósticos, análisis y posibles soluciones a los principales problemas del país, pero no de cualquier modo. El compromiso con la justicia social y la opción por los pobres, que brotan de su inspiración cristiana, obligan a la UCA a tener no solamente presente, sino como horizonte y lugar desde el cual pensar, la situación de las mayorías del país y de la región centroamericana.

Con un $40 \%$ de los salvadoreños viviendo en exclusión desde hace décadas, con los altos niveles de migración, con la situación de violencia y criminalidad, que afecta principalmente a los pobres, la Universidad tiene el compromiso de ponerse al servicio de esta parte de la población que sigue luchando por su liberación y que tiene derecho a una vida digna y con bienestar.
Es por ello que la UCA debe comprometerse especialmente con aquellas temáticas que supongan un cambio para esas mayorías, y aportar soluciones a sus aspiraciones y para el cumplimiento pleno de sus derechos humanos.

En ese sentido, la Universidad debe insistir en todo momento en que la investigación no es apolítica ni imparcial. Para la UCA, todo su quehacer -y por ende, también la investigación- debe estar parcializado en favor de la vida y liberación de las mayorías excluidas del actual sistema social y económico, y de una cultura que no favorece la emancipación de este pueblo (esta fue una de las insistencias del P. Ellacuría que nos dejó como legado).

d) Nuestra investigación, así como todo nuestro trabajo universitario está al servicio de un fin mayor

A diferencia de otras universidades que investigan para estar en los primeros lugares de los rankings que miden el número de investigaciones, patentes registradas $y$ publicaciones en revistas científicas y técnicas, la UCA busca otro fin, sin que ello signifique negar la importancia de lo primero.

La finalidad última y distintiva de la investigación de la UCA es aliviar el dolor de las víctimas de la injusticia social y de un sistema que margina casi a la mitad de la 
población, y ofrecer una vida digna para todos. Si nuestra investigación no coadyuva a ello, si no contribuye a hacer de nuestro mundo un lugar más humano, donde todos podamos vivir dignamente, donde la calidad de vida se mida por la realización y felicidad personal, por los niveles de humanización antes que por el nivel de ingreso, no tiene sentido investigar.

Venimos de un pasado de investigaciones importantes para el país. De una tradición de estudio y análisis de la realidad, de estudios en las áreas de las Ciencias Sociales y Políticas, estamos incursionando en investigaciones en el área de las ciencias y la tecnología. Un pasado que nos debe estimular a seguir en esa misma dirección. El Ing. Mayorga nos comentaba ayer que mucho del valioso trabajo de investigación que la UCA había producido en sus primeros 25 años, se realizó con grandes sacrificios, con un inmenso esfuerzo y con largas jornadas de trabajo y noches de desvelo. Ello mostraba la pasión puesta en el trabajo de la UCA en esa época. Debemos recuperar parte de esa mística, de esa pasión y compromiso por contribuir decididamente y beligerantemente a la construcción de una sociedad basada en la libertad, la justicia, la paz y la igual dignidad de la persona humana, personas que tienen el mismo derecho a ser felices y realizar sus proyectos de vida. $Y$ eso urge en nuestro país y en nuestra Universidad.

Deseamos que este Encuentro Nacional sobre investigación nos anime a continuar el trabajo y nos rete a seguir aportando desde la investigación al cambio social de nuestro país.

Antiguo Cuscatlán, 05 de noviembre de 2015 .

\section{Referencias}

- Misión de la Universidad Centroamericana "José Simeón Cañas". (Febrero de 2001). pp. 35-36. San Salvador, El Salvador. 